April 2021

\title{
Use of Artificial Intelligence to Determine Copyright Liability for Musical Works
}

Shine Sean Tu

West Virginia University College of Law, shine.tu@mail.wvu.edu

Follow this and additional works at: https://researchrepository.wvu.edu/wvlr

Part of the Law Commons

\section{Recommended Citation}

Shine S. Tu, Use of Artificial Intelligence to Determine Copyright Liability for Musical Works, 123 W. Va. L. Rev. 835 (2021).

Available at: https://researchrepository.wvu.edu/wvlr/vol123/iss3/6

This Article is brought to you for free and open access by the WVU College of Law at The Research Repository @ WVU. It has been accepted for inclusion in West Virginia Law Review by an authorized editor of The Research Repository@WVU. For more information, please contact ian.harmon@mail.wvu.edu. 


\title{
USE OF ARTIFICIAL INTELLIGENCE TO DETERMINE COPYRIGHT LIABILITY FOR MUSICAL WORKS
}

\author{
Shine Sean $T u^{*}$
}

\section{Abstract}

This article explores the use of Artificial Intelligence to help define the existing test for copyright infringement for musical works. Currently, the test for copyright infringement requires the jury or a judge to determine whether the parties' works are "substantially similar" to each other from the vantage point of the "ordinary observer." This "substantial similarity" test has been criticized at almost every level due to its inconsistent nature. Artificial Intelligence has evolved to the point where it can be used as a tool to resolve many of the current issues associated with the "substantial similarity" test when it comes to musical works. Specifically, courts would no longer have to rely on a battle of the experts or the use of lay observers to determine if a work is substantially similar to another work. Artificial Intelligence can be used to help establish copyright infringement in a way that is both less biased and more fact driven. Additionally, Artificial Intelligence algorithms could strengthen the notice function of copyrights by allowing alleged infringers a means by which to check ex ante if their work could be infringing.

I. INTRODUCTION

A. Substantial Similarity

1. Ninth Circuit Two-Part Extrinsic/Intrinsic Test ...............842

i. Part One-Objective Extrinsic Test.

ii. Part Two-Subjective Intrinsic Test .......................... 844

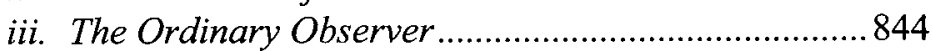

2. Second Circuit - The "Ordinary Observer" Test .............845

i. First Prong-Analysis and Dissection to

Determine "Copying".

ii. Second Prong-Improper

Appropriation/Illicit Copying

\footnotetext{
* Professor, West Virginia University College of Law. Sincere thanks to the many readers who offered comments on earlier drafts, including Mark Lemley, Amy Cyphert, Sam Perl, Jake Linford, and Michael Madison. This work was funded in part by the generous support of the West Virginia University College of Law Hodges Research Fund.
} 
3. Sixth and Tenth Circuit Abstraction-Filtration-Comparison Test.....

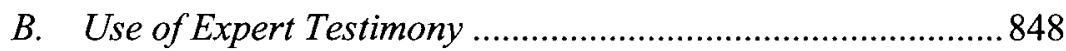

C. Scènes à Faire ............................................................... 850

D. Academic Response to Substantial Similarity and Expert Opinions.

III. BASICS OF MACHINE LEARNING ................................................8 854

A. Supervised Learning................................................... 855

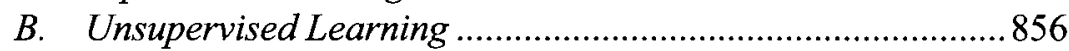

IV. USE OF ARTIFICIAL INTELLIGENCE IN THE

CURRENT COPYRIGHT INFRINGEMENT FRAMEWORK

A. General Principles-Use of Standard Algorithms for

Each Prong of the Infringement Analysis

B. Use of Unsupervised Learning Algorithms as an Expert for "Extrinsic Analysis" and "Copying" of

Musical Works.

1. Algorithm as an Expert Witness

2. Use of Machine Learning to Create a Scènes à Faire/Functional Harmony Library.

C. Use of Structured Learning Algorithms for "Intrinsic Analysis" and "Unlawful Appropriation".

D. Social Benefits Associated with Using AI To Determine Copyright Infringement.

1. Notice Function of Copyrights 863

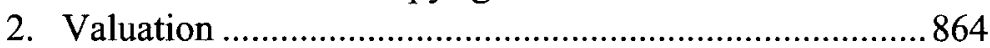

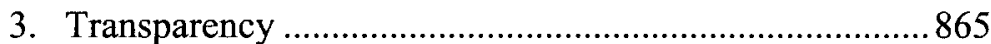

4. Move Control Back to the Creator ................................866

5. Allows for Multidimensional Analysis Without Loss of Notice Function 867

6. Consistent Application of Inputs ..................................868

E. Social Costs Associated with Using AI To Determine Copyright Infringement ......................................................................868

\section{INTRODUCTION}

Popular music has become a huge business with total revenue in 2019 of $\$ 11.1$ billion (up 13\% from 2018). ${ }^{1}$ The financial stakes have, therefore, risen

\footnotetext{
I Joshua P. Friedlander, Year-End 2019 RIAA Music Revenues Report 1 (2019) https://www.riaa.com/wp-content/uploads/2020/02/RIAA-2019-Year-End-Music-IndustryRevenue-Report.pdf.
} 
significantly with copyrights playing a pivotal role. ${ }^{2}$ Cases involving musical copyright infringement are complex and notoriously unpredictable. This is in large part because the test for copyright infringement is fraught with problems. Accordingly, record labels, artists, songwriters, and producers are increasingly moving towards prevention (by changing their songs) or insurance to limit their risks. Society loses important expression when artists stop producing their songs or unnecessarily change their songs in fear of litigation. Litigation based on copyrights that are not substantially similar to referenced work impedes the goal of the copyright framework, which is to promote the progress of science and the useful arts. ${ }^{3}$ Additionally, consumer costs are increased if record labels and producers have to shift the costs of liability insurance onto consumers.

Musicians have been borrowing musical elements from prior works when composing new music since at least the 17 th century. ${ }^{4}$ As noted by Edward Lee, the extent of musical borrowing "is so large that it has spawned an entire field of research among musicologists and other scholars." Musical borrowing can take many forms, such as "transcription, variations, quotation, paraphrase, parody, modeling, allusion, [and] sampling" among many others. ${ }^{6}$ The real legal problems at issue with musical borrowing are how much borrowing is too much, and when do we impose copyright liability?

The legal test used to determine copyright liability is one of the most maligned tests in the legal field. Compounding the issue is the fact that this test is completely judge-made law, as Congress has never given the standard, and the Supreme Court has not weighed in to bring consistency in this area of law. ${ }^{7}$ The test is "mystifying for both courts and litigants," "notoriously confusing and confused," and arguably "more difficult than creating the work in the first place." "Judge Hand even candidly observed, "no principle can be stated as to when an imitator has gone beyond copying the 'idea,' and has borrowed its 'expression.' Decisions must therefore inevitably be ad hoc." " This is even more important considering that courts, such as in the case involving Robin Thicke

2 See generally Jessica Litman, Digital Copyright (2001); Michael W. Carroll, The Struggle for Music Copyright, 57 FLA. L. REV. 907 (2005).

$3 \quad$ U.S. ConsT. art. I, $\S 8$, cl. 8.

$4 \quad$ Edward Lee, Fair Use Avoidance in Music Cases, 59 B.C. L. REv. 1874, 1890 (2018).

$5 \quad I d$.

$6 \quad$ Id. (citing Musical Borrowing \& Reworking: An Annotated Bibliography, CTR. FOR HIST. MusiC THEORY \& LiTERATURE, http://chmtl.indiana.edu/borrowing/ (last visited Feb. 25, 2021)).

7 See Melville Nimmer, Nimmer on COPYright $\S 13.03$ [A] (2013).

$8 \quad$ Nicole K. Roodhuyzen, Do We Even Need a Test? A Reevaluation of Assessing Substantial Similarity in a Copyright Infringement Case, 15 J.L. \& POL'Y 1375, 1384 (2007).

9 Rebecca Tushnet, Worth A Thousand Words: The Images of Copyright, 125 HARV. L. REV. $683,716-17$ (2012).

10 Roodhuyzen, supra note 8, at 1375.

11 Peter Pan Fabrics, Inc. v. Martin Weiner Corp., 274 F.2d 487, 489 (2d Cir. 1960). 
and Pharrell Williams' "Blurred Lines" versus Marvin Gaye's "Got to Give it Up," have moved from considering only melody and lyrics (unidimensional similarity) to considering other elements, such as harmony, rhythm, orchestration, timbre, tempo, and pitch (multidimensional similarity). ${ }^{12}$ In sum, the test for copyright infringement is a mess, and the tests for substantial similarity mirror Justice Stewart's famous statement, "I know it when I see it."13

In general, the prima facie case of copyright infringement requires three elements: (1) ownership of a valid copyright in the work, (2) actual copying by the defendant ("extrinsic/copying" prong), and (3) the defendant's copying constituting an improper appropriation ("intrinsic/unlawful copying" prong).$^{14}$ This Article focuses only on elements two and three. The "extrinsic/copying" prong requires that the alleged infringer "copied" the referenced work and did not independently create the work. The "intrinsic/unlawful copying" prong requires that the alleged infringer copied enough of the referenced work's original expression to create a "substantially similar" work.

Much of the problem with the current test for copyright infringement for music lies in the fact that the infringement analysis does not allow for expert testimony in every step of the analysis. Not only is the cost of expert testimony prohibitive for many litigants, but courts specifically disallow expert testimony in some parts of the infringement analysis. When not informed by expert testimony, all tests for musical copyright infringement can be overly narrow. For example, without expert testimony, the test is underinclusive because the fact finder may not be qualified to determine the responses of the particular audience for whom the music has been composed. ${ }^{15}$ This Article argues that Artificial Intelligence ("AI") may not only offer a solution to the expert analysis issue but may also result in some consistency when it comes to copyright infringement of musical works.

AI algorithms are already being used to identify and remove illicit content from websites such as YouTube, Google, Facebook, and other online platforms. ${ }^{16}$ Accordingly, AI is already being used to detect and determine

12 Joseph P. Fishman, Music as a Matter of Law, 131 HARV. L. REv. 1861, 1872-73 (2018); see also Ben Sisario \& Noah Smith, "Blurred Lines" Infringed on Marvin Gaye Copyright, Jury Rules, N.Y. TIMES (Mar. 10, 2015), https://www.nytimes.com/2015/03/1 1/business/media/blurredlines-infringed-on-marvin-gaye-copyright-jury-rules.html?searchResultPosition=1.

13 Jacobellis v. Ohio, 378 U.S. 184, 197 (1964) (Stewart, J., concurring); see also Roodhuyzen, supra note 8, at 1376.

14 Marshall A. Leaffer, Understanding Copyright Law 413 (7th ed. 2019).

15 Michael Der Manuelian, The Role of the Expert Witness in Music Copyright Infringement Cases, 57 FordHAM L. Rev. 127, 144 (1988).

16 Dan Burk, Algorithmic Fair Use, 86 U. CHI. L. REv. 283, 284 (2019); Maayan Perel \& Niva Elkin-Koren, Accountability in Algorithmic Copyright Enforcement, 19 STAN. TECH. L. REV. 473, 478-81 (2016); Matthew Sag, Internet Safe Harbors and the Transformation of Copyright Law, 93 Notre Dame L. Rev. 499, 539, 543-44 (2017) (naming "Scribid, 4shared, Dropbox, YouTube, Facebook, SoundCloud, Twitch, TuneCore, Tumblr, Veoh, and Vimeo" as companies already 
copyright infringement when it comes to the digital media. ${ }^{17}$ Some commentators warn of the possible costs associated with reliance on AI, such as "ersatz objectivity, diminished decisional transparency, and design biases." 18 With that said, automated filtering systems protect large companies from the uncertainty of catastrophic liability. Specifically, for platforms hosting user-generated content or video and music content, use of automated filtering systems can help these platforms take advantage of the Digital Millennium Copyright Act's ("DMCA") safe harbor from copyright litigation. 19 This Article suggests expanding the use of AI to act not only as a filter but also as an "expert" when it comes to infringement of musical copyrights.

AI has the ability to transparently assess substantial similarity not only in the "extrinsic/copying" prong of copyright liability, but AI also has the ability to assess the "intrinsic/unlawful copying" prong of copyright liability. Expert testimony is already being used for the "extrinsic/copying" prong, and AI would simply add an additional layer of transparency in this extrinsic step because the algorithm that would be used could be agreed upon as an industry standard and could even be adjusted based on different genres of music. For the first "extrinsic/copying" prong, the algorithm could "learn" using an "unstructured learning" system. ${ }^{20}$ Separately, AI could be used in the "intrinsic/unlawful copying" prong through "structured learning" and improving the algorithm by polling different users about similarity between songs. ${ }^{21}$ This would allow the AI to improve the algorithm based on the actual "intended audience" for the musical works. Finally, unlike many other proposals that try to overhaul musical copyright infringement, AI can accommodate a wide range of musical forms and a wide range of musical creativity.

Part II of this Article defines the different tests that are currently being used to determine copyright infringement and some of the shortcomings associated with these tests when it comes to musical works. Part III gives a brief primer on AI and machine learning tools. Part IV describes the use of these new technologies to determine copyright liability for musical works and the associated costs and benefits. Finally, Part V concludes.

using automated copyright enforcement techniques); Henning Grosse Ruse-Khan, Automated Copyright Enforcement Online: From Blocking to Monetization of User-Generated Content, JorNT $\begin{array}{llll}\text { PIJIP/TLS RSCH. PAPER } & \text { SERIES }\end{array}$ https://digitalcommons.wcl.american.edu/cgi/viewcontent.cgi?article=1053\&context=research (last visited Feb. 17, 2021).

17 How Al Could Help Fight Plagiarism in the Music Business, INQUIRER.NET (Dec. 9, 2020,

3:48 PM), https://technology.inquirer.net/106285/how-ai-could-help-fight-plagiarism-in-themusic-business.

18 Burk, supra note 16, at 286; see also Sag, supra note 16.

19 Sag, supra note 16.

20 See infra Section 0.B.

21 See infra Section 0.C. 


\section{CURRENT TESTS FOR COPYRIGHT INFRINGEMENT}

In general, the prima facie case of copyright infringement requires three elements: (1) ownership of a valid copyright in the work, (2) actual copying by the defendant, and (3) the defendant's copying constituting an improper appropriation. ${ }^{22}$ Ownership of a valid copyright requires originality, fixation, copyrightable subject matter, and compliance with statutory formalities. To meet the "copying" requirement, ${ }^{23}$ plaintiffs must show that defendants actually copied the copyrighted work rather than creating their own work. ${ }^{24}$ Actual copying can also be proven by demonstrating that the defendant had access to the plaintiff's work and by a showing of probative similarity between the competing works. ${ }^{25}$ Finally, to show that a defendant's copying constitutes an improper appropriation, the plaintiff must show that the defendant took a sufficient amount of the original expression to create a "substantially similar" work.

Infringement of musical works poses some unique problems for judges and juries. Specifically, music is an intuitive art that can be nonverbal and nonvisual. ${ }^{26}$ Additionally, there are a limited number of notes and chords that exist and even fewer notes that sound harmonious together. Accordingly, there are common themes and sounds that frequently appear in various compositions, especially in popular music. ${ }^{27}$ Adding to this complexity is the fact that melody and lyrics are not the only elements that can establish copyright liability. Factors, such as rhythm, harmony, orchestration, and organizational structures, can play a major role in determining substantial similarity. ${ }^{28}$ Thus, traditional infringement analysis can be unreliable when applied to music.

\footnotetext{
22 LEAFFER, supra note 14.

23 Copying includes reproduction, creating derivative works, unlawful distribution, and unlawful display as well as performance rights. Id. at 414 .

24 Independent creation is specifically not included as "copying" the work. Id.

25 Swirsky v. Carey, 376 F.3d 841, 844 (9th Cir. 2004). In a recent case, the Ninth Circuit struck down its own "inverse ratio rule," which dictated that there is "a lower standard of proof of substantial similarity when a high degree of access is shown." Skidmore v. Led Zeppelin, 352 F.3d 1051, 1066 (9th Cir. 2020) (citing Three Boys Music Corp. v. Bolton, 212 F.3d 477, 485 (9th Cir. 2000)). This ruling brings the Ninth Circuit in line with the Second, Fifth, Seventh, and Eleventh Circuits. Id.

26 E. Scott Fruehwald, Copyright Infringement of Musical Compositions: A Systematic Approach, 26 AKRON L. REV. 15, 15 (1992).

27 Id. at 30; see also Random804, Axis of Awesome-4 Four Chord Song (with Song Titles), YouTUBE (Dec. 10, 2009), https://www.youtube.com/watch?v=5pidokakU4I.

28 Fishman, supra note 12, at 1866; see also Williams v. Gaye, 895 F.3d 1106, 1117 (9th Cir. 2018).
} 


\section{A. Substantial Similarity}

Even if the plaintiff has shown that the defendant copied the plaintiff's work, the test for infringement is still not complete. A court must determine if the quantity copied is sufficient to constitute illegal appropriation. Courts require "substantial similarity" between the copyrighted work and the allegedly infringing work. Thus, "even where the fact of copying is conceded, no legal consequences will follow from that fact unless the copying is substantial."29

Substantial similarity is an inquiry that is difficult and perplexing for both courts and litigants. Substantial similarity is a legal inquiry that is guided by several principles. The fact finder should first consider only similarities involving the protected expressive elements and not those elements that are in the public domain. Only the elements of original expression that were copied are protected by copyright law and thus relevant for this analysis.

The requirement of substantial similarity is complicated ${ }^{30}$ because copyrighted works almost always contain original expression mixed with public domain materials, such as facts, ideas, functional aspects, ${ }^{31}$ non-original elements, government works, and other uncopyrightable materials. ${ }^{32}$ Courts continue to struggle to develop a legal standard that balances the rights of all parties. On the one hand, courts need to protect the copyright holder and leave intact the incentive to create the work in the first place. On the other hand, the courts need to be careful not to extend the scope of copyright protection and hinder the "progress of science and the useful arts." 33

The complexity of the substantial similarity test is magnified by the fact that the test is applied differently in different circuits. To determine substantial similarity, the Fourth, Eighth, and Ninth Circuits employ a two-part test: an objective extrinsic test and a subjective intrinsic test. In contrast, the First,

\footnotetext{
29 Newton v. Diamond, 388 F.3d 1189, 1193 (9th Cir. 2004).

30 To add one additional layer of complexity, some circuits diverge from their normal test when it comes to copyrights in software. However, copyrights in software are beyond the scope of this Article. See Mark A. Lemley, Our Bizarre System for Proving Copyright Infringement, 57 J. COPYRIGHT SOC'Y U.S.A. 719, 733-36 (2010) (showing the Second, Fifth, and Tenth Circuits' use of the abstraction-filtration-comparison test when it comes to copyrights in software and showing that the Third, Fifth, Ninth, and Tenth Circuits expand the use of expert testimony when dealing with software copyrights).

31 Interestingly, some commentators have argued for "harmonic functionality." For example, Sergiu Gherman argues that certain simple harmonies should be unprotectable based on notions of music theory and the acoustic nature of sound. See Sergiu Gherman, Harmony and Its Functionality: A Gloss on the Substantial Similarity Test in Music Copyrights, 19 FORDHAM Intell. Prop. Media \& ENT. L.J. 483, 485 (2009).

32 LEAFFER, supra note 14, at 420; see also David May, "So Long as Time Is Music": When Musical Compositions Are Substantially Similar, 60 S. CAL. L. REV. 785, 785-90 (1987).

U.S. Const. art. I, $\S 8$, cl. 8 .
} 
Second, Third, Fifth, and Seventh Circuits employ an "ordinary observer" test. ${ }^{34}$ The Sixth and Tenth Circuits use an abstraction-filtration-comparison test. ${ }^{35}$ While most courts will use the core principles set out in these three tests, many courts will use variations of these tests. ${ }^{36}$

The Ninth Circuit's test requires an "intrinsic" and "extrinsic" analysis. The "extrinsic" portion of the substantial similarity determination focuses on which portions of the allegedly infringed song are public domain and which parts are original expression. Expert testimony can be used for the "extrinsic" analysis. The "intrinsic" portion of the substantial similarity determination is intrinsic because it does not depend on the type of external criteria and analysis associated with the extrinsic portion of the test. Thus, "because this is an intrinsic test, analytic dissection and expert testimony are not appropriate." 37

The Second Circuit's two-part test requires (1) a determination of "copying" and then (2) the trier of fact must determine whether the copying is sufficiently substantial to constitute "unlawful appropriation." "38 Thus, copying only trivial aspects of another's work will not result in liability. Infringement only occurs when the copying is sufficiently extensive. ${ }^{39}$ In this second step, the trier of fact applies the "ordinary observer" test, unaided by dissection or expert testimony, to determine whether the copying resulted in substantial similarity between the works. ${ }^{40}$

Finally, the abstraction-filtration-comparison test, used by the Sixth and Tenth Circuits, requires the court to (1) abstract and separate the ideas and other non-protectable materials, then (2) filter out the non-protectable components from the expressive materials, and then (3) compare the remaining protected elements to the allegedly infringed work to determine if the two works are substantially similar. ${ }^{41}$

\section{Ninth Circuit Two-Part Extrinsic/Intrinsic Test}

As noted above, the Ninth Circuit employs a two-part test: an objective extrinsic test and a subjective intrinsic test. In sum, the first part of the test compares the objective similarities of specific expressive elements in the two

\footnotetext{
34 Gabriel Godoy-Dalmau, Substantial Similarity: Kohus Got It Right, 6 MrCH. Bus. \& ENTREPRENEURIAL L. REV. 231, 243 (2017).

35 Id. at $247-48$.

36 For an analysis of the variations on these tests, see id. at 243-49.

37 Sid \& Marty Krofft Television Prods., Inc. v. McDonald's Corp., 562 F.2d 1157, 1164 (9th Cir. 1977).

38 Concrete Mach. Co. v. Classic Lawn Ornaments, Inc., 843 F.2d 600, 608-09 (1st Cir. 1988).

$39 \quad$ Id.

$40 \quad$ Id. at 608.

41 See Kuhos v. Mariol, 328 F.3d 848, 855 (6th Cir. 2003); Gates Rubber Co. v. Bando Chem. Indus., 9 F.3d 823, 841-42 (10th Cir. 1993).
} 
works. ${ }^{42}$ The second, intrinsic, part of the test looks for "similarity of expression from the standpoint of the ordinary reasonable observer, with no expert assistance. ${ }^{.43}$

\section{i. Part One-Objective Extrinsic Test}

The first prong of the test considers whether the two works share a similarity of ideas ${ }^{44}$ and expression as measured by external, objective criteria, which is a question of law. This extrinsic step can require "analytical dissection of a work and expert testimony." "Analytical dissection" requires the court to break down the works into their constituent elements and compare those elements for proof of copying as measured by "substantial similarity." This first prong helps the trier of fact determine which elements of the allegedly infringed work are unprotectable elements ${ }^{46}$ (such as scènes à faire, public domain, or uncopyrightable ideas) and which elements are protectable original expression.

When it comes to musical works, expert testimony can come from music theoreticians, composers, musicologists, and forensic musicologists. These experts can dissect both works measure-by-measure to determine whether the defendant appropriated protectable elements from the plaintiff's work. ${ }^{47}$ This analysis may take into account elements such as "melody, harmony, rhythm, pitch, tempo, phrasing, structure, chord progressions, and lyrics. ${ }^{, 48}$ Additionally, elements such as timbre, tone, spatial organization, consonance, dissonance, accents, note choice, combinations, interplay of instruments, basslines, and new technological sounds can also be taken into account. ${ }^{49}$ Forensic musicologists can compare different works by transcribing similar parts, transposing them into the same key for ease of comparison, then examining melodic, harmonic, lyric, rhythmic, and structural elements. Forensic musicologists then can prioritize and examine closely those elements that are important to the work. For example, in Hip Hop, rhythm is often more important than melody, but the rhythm of words,

42 Skidmore as Tr. for Randy Craig Wolfe Tr. v. Led Zeppelin, 952 F.3d 1051, 1064 (9th Cir. 2020) (citing Cavalier v. Random House, Inc., 297 F.3d 815, 822 (9th Cir. 2002)).

$43 \quad$ Id.

44 Note that the extrinsic test examines the similarity of ideas and expression. Ideas by themselves are not within the scope of copyright protection; only expression of the idea can be protected by copyright.

45 Swirsky v. Carey, 376 F.3d 841, 845 (9th Cir. 2004).

46 Note, however, that even if the individual elements are not protectable, a court could find that the combination and arrangement of these elements (selection, coordination, and arrangement) are protectable. See Roodhuyzen, supra note 8, at 1399.

$47 \quad$ Swirsky, 376 F.3d at 849.

48 Id.; see also Ellis v. Diffie, 177 F.3d 503, 506 (6th Cir. 1999).

49 Swirsky, 376 F.3d at 849. 
accent patterns, and intonations might be important if they are the same in two works. ${ }^{50}$ In contrast, folk and country music are more lyric driven. ${ }^{51}$

If there is copying of protectable material, then the court will move to the second "intrinsic" part of the test. Again, only the protected elements of the copyrighted work are essential for substantial similarity. Unprotected elements in a plaintiff's work can be copied with no liability.

\section{ii. Part Two-Subjective Intrinsic Test}

The second part of the test asks if the works are intrinsically similar to each other. ${ }^{52}$ This prong examines the ordinary observer's subjective impressions of the similarities between the two works. This question of fact is for the jury and is the exclusive jurisdiction of the jury. ${ }^{53}$ The jury determines if the works are subjectively similar to each other. The intrinsic test asks whether an "ordinary reasonable observer" would find a substantial similarity of expression of the shared idea. ${ }^{54}$ Accordingly, the members of the jury are asked whether the total feel and total concept of the two works, in their ordinary and reasonable perception, are substantially similar. ${ }^{55}$ Additionally, since the response is based on the ordinary reasonable observer, no expert testimony is permitted in this prong of the infringement analysis. ${ }^{56}$

\section{iii. The Ordinary Observer}

When it comes to the Ninth Circuit's test, courts that follow Sid \& Marty Krofft Television v. McDonald's Corp. ${ }^{57}$ are more willing to treat the "ordinary

50 See Colorado Law, Silicon Flatirons Conference: Lay Listeners, Sheet Music \& Chord

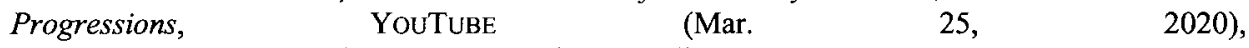
https://www.youtube.com/watch?v=RTNufsgy22c\&list=PLwFq2GLisUiWv6s7HVKFQp39w314ijWq\&index $=2 \& t=0$ s.

$51 \quad I d$.

52 Kouf v. Walt Disney Pictures \& Television, 16 F.3d 1042, 1045 (9th Cir. 1994) (stating that a "plaintiff who cannot satisfy the extrinsic test necessarily loses on summary judgment, because a jury may not find substantial similarity without evidence on both the extrinsic and intrinsic tests").

53 Shaw v. Lindheim, 919 F.2d 1353, 1358 (9th Cir. 1990) (showing that the trier of fact must decide under the intrinsic test whether there is substantial similarity in the expressions of the ideas so as to constitute infringement and that the "intrinsic test for expression is uniquely suited for determination by the trier of fact").

54 Apple Comput., Inc. v. Microsoft Corp., 35 F.3d 1435, 1442 (9th Cir. 1994).

55 Swirsky v. Carey, 376 F.3d 841, 847 (9th Cir. 2004); Three Boys Music Corp. v. Bolton, 212 F.3d 477, 485 (9th Cir. 2000).

56 Sid \& Marty Krofft Television v. McDonald's Corp., 562 F.2d 1157, 1164 (9th Cir. 1977); see also NimMER, supra note 7, at § 13.03 [E][3][b][i].

$57 \quad 562$ F.2d 1157 (9th Cir. 1977). 
observer" as the likely customer of the copyrighted products, regardless of if that customer is a member of the jury. ${ }^{58}$ Specifically, the Fourth Circuit has found that "where the intended audience is significantly more specialized than the pool of lay listeners, the reaction of the intended audience would be the relevant inquiry." 59

Both the Fourth and the Sixth Circuits narrow the ordinary observer analysis to that of an ordinary intended audience member. The Fourth Circuit in Dawson v. Hinshaw Music Inc. ${ }^{60}$ argues that the ordinary observer test should be viewed as the ordinary intended audience member. ${ }^{61}$ Specifically, the court stated that only when "the lay public fairly represents the works' intended audience" may the court use the ordinary lay observer as the ordinary person for the ordinary person test. ${ }^{62}$ Similarly, the Sixth Circuit in Kohus v. Mario ${ }^{63}$ focuses not on the lay observer, but on the intended audience member, and also allows for the use of experts to help the trier of fact make the substantial similarity determination from the perspective of the intended audience member. ${ }^{64}$

\section{Second Circuit-The "Ordinary Observer" Test}

The Second Circuit has a two-step test. The first step involves analysis and dissection, and the second step involves an "ordinary observer" test. This test asks "whether an average lay observer would recognize the alleged copy as having been appropriated from the copyrighted work." 65

\section{i. First Prong-Analysis and Dissection to Determine "Copying"}

The first prong of the ordinary observer test determines if the alleged infringer copied the referenced work. Even if the work is similar, there is no copyright liability if the alleged infringer independently created the work. Similar to the first prong of the Ninth Circuit test, this step involves separation

\footnotetext{
$58 \quad$ Lemley, supra note 30.

59 Dawson v. Hinshaw Music Inc., 905 F.2d 731, 734 (4th Cir. 1990).

$60 \quad I d$.

$61 \quad I d$. at 734 .

62 Id. at 733; see also B. MacPaul Stanfield, Finding the Fact of Familiarity: Assessing Judicial Similarity Tests in Copyright Infringement Actions, 49 DRAKE L. REV. 489, 504 (2001).

$63 \quad 328$ F.3d 848 (6th Cir. 2003).

64 Id. at 857 (stating that "the second prong of the substantial similarity test should focus on the intended audience. This will ordinarily be the lay public . . . But in cases where the audience for the work possesses specialized expertise that is relevant to the purchasing decision and lacking in the lay observer, the trier of fact should make the substantial similarity determination from the perspective of the intended audience. Expert testimony will usually be necessary to educate the trier of fact in those elements for which the specialist will look.").
}

65 Knitwaves, Inc. v. Lollytogs, Ltd., 71 F.3d 996, 1002 (2d Cir. 1995). 
and "dissection" of the unprotected material from the protected copyrighted materials. Also similar to the Ninth Circuit, the Second Circuit allows for expert testimony to satisfy the first prong of this test.

This first prong can be satisfied if the defendant admitted to copying or if, by circumstantial evidence, the trier of fact may reasonably infer copying. ${ }^{66}$ Copying can be inferred "[i]f there is evidence of access and similarities exist . . . [and] the similarities are sufficient to prove copying." 67

This test has been criticized in part because the trier of fact is exposed to expert evidence in the first prong but then must "ignore or 'forget' that evidence in analyzing the problem under the [second prong]." ${ }^{\circ 8}$ It may not be possible, however, for a trier of fact to hear expert testimony on the issue of coping but then discount that testimony to determine if there was too much copying. This is especially difficult when it comes to complex works such as computer programs or musical works. ${ }^{69}$

\section{ii. Second Prong-Improper Appropriation/Illicit Copying}

The second step determines if an ordinary observer could recognize if the defendant "appropriated something which belongs to the plaintiff." 70 The trier of fact, however, still must consider the work as a whole and use the "total concept and feel" analysis. ${ }^{71}$ Accordingly, the trier of fact must now determine if the copying "went too far as to constitute improper appropriation." so, the trier of fact must look to only the copyrightable elements from the first prong of the test and determine if enough of that copyrightable material was taken to be substantially similar (and thus create copyright liability). Interestingly, the Second Circuit for some types of copyrighted works has enhanced the ordinary observer test to include a "more discerning 'ordinary observer" for works that have extensive similarity in unprotected material. ${ }^{73}$ Finally, similar to the "intrinsic" prong of the Ninth Circuit test, the Second Circuit does not allow the use of expert testimony to determine if there was too

\footnotetext{
66 Craig Joyce, Tyler Ochoa, Michael Carroll, Marshall Leaffer et al., Copyright LAW 648 (10th ed. 2016).

67 Arnstein v. Porter, 154 F.2d 464, 468 (2d Cir. 1946).

68 Whelan Assocs. Inc. v. Jaslow Dental Lab'y, Inc., 797 F.2d 1222, 1232-33 (3d Cir. 1986).

69 Roodhuyzen, supra note 8, at 1391.

70 Arnstein, 154 F.2d at 473.

71 Knitwaves, Inc. v. Lollytogs Ltd., 71 F.3d 996, 1003 (2d Cir. 1995).

72 Arnstein, 154 F.2d at 468.

73 Folio Impressions, Inc. v. Byer Cal., 937 F.2d 759, 766 (2d Cir. 1991).
} 
much copying. "Too much copying" is determined solely by the trier of fact in the second prong of the ordinary observer test. ${ }^{75}$

However, when it comes to musical works, the Second Circuit still follows Arnstein v. Porter. ${ }^{76}$ In Arnstein, the court gave the following analysis:

The proper criterion on that issue is not an analytic or other comparison of the respective musical compositions as they appear on paper or in the judgement of trained musicians. The plaintiff's legally protected interest is not, as such, his reputation as a musician but his interest in the potential financial returns from his compositions which derive from the lay public's approbation of his efforts. The question, therefore, is whether defendant took from plaintiff's works so much of what is pleasing to the ears of lay listeners, who comprise the audience for whom such popular music is composed, that the defendant wrongfully appropriated something which belongs to the plaintiff. $^{77}$

The main problem with this use of expert witnesses is that it may be impossible for the court to rely on expert testimony for the issue of copying but not on the issue of too much copying because these two questions necessarily blend together.

Additionally, when it comes to musical works, not all courts use a heightened observer test. For example, while the Fourth Circuit stated that it might allow use of a specialized observer for music, ${ }^{78}$ the Second Circuit has specifically rejected this narrower standard for music. ${ }^{79}$

\section{Sixth and Tenth Circuit Abstraction-Filtration-Comparison Test}

The Sixth and Tenth Circuits use an abstraction-filtration-comparison test. The abstraction step requires the court to separate ideas and functional and scènes à faire (non-protectable) material(s) from the expression (protectable) material(s). The court then filters out the non-protectable components of the product from the original expression. Some courts will allow expert testimony

\footnotetext{
$74 \quad$ Roodhuyzen, supra note 8, at 1388.

75 See Knitwaves, Inc., 71 F.3d at 1002.

$76 \quad 154$ F.2d. 464 (2d Cir. 1946).

$77 \quad$ Id. at 473 .

78 Dawson v. Hinshaw Music Inc., 905 F.2d 731, 736-38 (4th Cir. 1990).

79 Arnstein, 154 F.2d at 468 (stating that "the test is the response of the ordinary lay hearer; accordingly, on that issue, 'dissection' and expert testimony are irrelevant").
} 
for this filtration step. ${ }^{80}$ The court then compares the remaining protected elements to the allegedly infringed work to determine if the two works are substantially similar. ${ }^{81}$ Finally, courts use the ordinary observer standard on the comparison analysis. ${ }^{82}$

This test suffers from the same problems that plague the Ninth Circuit extrinsic/intrinsic test. Specifically, courts are required to separate out the nonprotected ideas/functions from the protected expressions. ${ }^{83}$ However, there is very little guidance on how to complete this abstraction or filtration step, and also the Sixth and Tenth Circuits' approach does not give guidance on how much similarity is enough to impose liability on an alleged infringer.

\section{B. Use of Expert Testimony}

A listener needs no expert or specialized knowledge to appreciate music. However, expert knowledge is necessary for comparing two musical works for infringement. Even though there is an almost unlimited number of permutations of notes on a scale, there are only a few that are pleasing, and still fewer that "suit the infantile demands of the popular ear."\$4

The use of expert testimony varies depending on the work (songs versus movies versus books, etc.) at issue as well as the different circuits. Plaintiffs commonly introduce the testimony of expert witnesses to strengthen and legitimize their claims. Both parties come equipped with experts resulting in a battle of the experts (1) constituting a significant segment of the trial ${ }^{85}$ and (2) sometimes creating great confusion for the trier of fact. However, there have been significant limitations imposed on expert testimony when it comes to musical works. ${ }^{86}$

The Second Circuit, in its two-part inquiry, allows experts to be used on the "dissection" step (the first part of the two-part inquiry). Expert testimony on this step helps the trier of fact determine whether the similarities are sufficient to prove "copying" from the protected work. ${ }^{87}$ In fact, in some cases, expert

\footnotetext{
80 Kohus v. Mariol, 328 F.3d 848, 856 (6th Cir. 2003) (stating that on the filtration step "expert testimony will likely be required to establish what elements, if any, are necessary to the function of [the item in question]").

81 Country Kids 'N City Slicks, Inc. v. Sheen, 77 F.3d 1280, 1284-85 (10th Cir. 1996); see also Kohus, 328 F.3d at 853.

82 Country Kids 'N City Slicks, Inc., 77 F.3d at 1288.

83 Id.

84 Darrell v. Joe Morris Music Co., 113 F.2d 80, 80 (2d Cir. 1940).

85 Der Manuelian, supra note 15 , at 128.

86 Id.; see also Arnstein v. Porter, 154 F.2d 464 (2d Cir. 1946); Sid \& Marty Krofft Television v. McDonald's Corp., 562 F.2d 1157 (9th Cir. 1977).

87 Arnstein, 154 F.2d at 468.
} 
testimony is required rather than permissive. ${ }^{88}$ When it comes to musical works, the Second Circuit addressed the issue in Arnstein v. Porter, where the court stated that expert testimony was relevant only to the determination of whether two works were similar enough to establish copying but not to the question of improper appropriation. ${ }^{89}$ Similarly, in Repp $v$. Webber, ${ }^{90}$ the Second Circuit elaborated on the role of the musical expert by stressing the critical role expert testimony can play in determining similarity. ${ }^{91}$ The Repp court effectively ruled that expert testimony that supports a claim of striking similarity can satisfy the first component (actual copying) of an infringement action even in the absence of "proof of access." 92

In Concrete Machinery v. Classic Lawn Ornaments, ${ }^{93}$ the First Circuit has elaborated on the "copying" portion of the test. In Concrete Machinery, the First Circuit stated that "by dissecting the accused work and identifying those features which are protected in the copyrighted work, the court may be able to determine as a matter of law whether or not the former has copied protected aspects of the latter." 94 Furthermore, the "copying" inquiry also helps determine those aspects of the work that are protected by the copyright and that should be considered in the subsequent comparative analysis under the ordinary observer test. $^{95}$

The Ninth Circuit, in its "extrinsic test" also allows for expert testimony to help the trier of fact with the specific criteria which can be listed and analyzed. Specifically, in Krofft, the court stated that the extrinsic test depends "on specific criteria which can be listed and analyzed. ... [Thus] analytic dissection and expert testimony are appropriate." 96 Thus, the Ninth Circuit allows for the use of expert testimony to help the trier of fact analyze the similarity of ideas (the alleged infringer is allowed to use ideas) but does not allow for expert testimony to help the trier of fact analyze similarity of expression, which is part of the

88 See, e.g., Testa v. Janssen, 492 F. Supp. 198, 203 (W.D. Pa. 1980) (Expert testimony was required when plaintiff sought to establish striking similarity.).

89 Arnstein, 154 F.2d at 468.

$90 \quad 132$ F.3d 882 (2d Cir. 1997).

$91 \quad$ Id. at 892 .

$92 \quad$ Id. at 889.

$93 \quad 843$ F.2d 600 (1st Cir. 1988).

$94 \quad$ Id. at 608.

$95 \quad$ Id.

96 Sid \& Marty Krofft Television v. McDonald's Corp., 562 F.2d 1157, 1164 (9th Cir. 1977). 
"intrinsic" analysis. ${ }^{97}$ These criteria include the type of copyrighted work involved, the materials used, and the setting for the subject. ${ }^{98}$

The Sixth Circuit uses expert testimony when the subject matter is complex. However, the court noted that if the subject matter is something like a literary work aimed at a general audience, expert testimony will seldom be necessary to determine substantial similarity. ${ }^{99}$

The Seventh Circuit, which follows the Second Circuit's "ordinary observer" test, has used expert testimony on both the first "copying" prong and also the second improper appropriation prong. ${ }^{100}$ Similarly, the First Circuit, which also follows the "ordinary observer" test, also allows expert testimony to help with the dissection analysis, even when copying has been proven in the first step. $^{101}$

The Eighth Circuit, in Moore v. Columbia Pictures Industries Inc., ${ }^{102}$ also used an expert witness. ${ }^{103}$ However, the court in Moore distinguished between qualifications of experts in separate musical genres. Specifically, the court admitted expert testimony but then discounted the testimony because the expert "could not classify the songs as part of a particular genre." 104 Furthermore, the expert conceded that he had heard of the term "hip-hop" but had no understanding of what it meant. ${ }^{105}$

\section{Scènes à Faire}

One important wrinkle in the substantial similarity test is the application of the scènes à faire doctrine. The scènes à faire doctrine prevents copyright liability for "stock characters, settings or events that are common to a particular subject matter or medium because they are commonplace and lack originality." 106 The basic policy behind the scènes à faire doctrine is that granting copyright protection over general themes will hinder others from subsequent creation of expressive works. Thus, expression that is indispensable for a common theme will remain in the public domain to benefit all, thereby

\footnotetext{
97 Id. (stating that "it is intrinsic because it does not depend on the type of external criteria and analysis which marks the extrinsic test.... Because this is an intrinsic test, analytic dissection and expert testimony are not appropriate.").

98 Lemley, supra note 30, at 723.

99 Stromback v. New Line Cinema, 384 F.3d 283, 293-95 (6th Cir. 2004).

100 Susan Wakeen Doll, Inc. v. Ashton Drake Galleries, 272 F.3d 441, 451 (7th Cir. 2001).

101 Yankee Candle Co. v. Bridgewater Candle Co., 259 F.3d 25, 33-34 (1st Cir. 2001).

102972 F.2d 939 (8th Cir. 1992).

$103 \quad I d$. at 945.

$104 \quad$ Id. at 946.

105 Id.

106 NIMMER, supra note $7, \S 313.4[1]$.
} 
immunizing the author from liability created from "incidents or plot that necessarily follows from a common theme or setting." 107

Procedurally, there is some inconsistency as to how to apply the scènes à faire (and merger) doctrine. Some courts use it as a bar to copyrightability, others use it as a defense to infringement. ${ }^{108}$ Depending on the local rules, the burden of proof will lie either with the plaintiff, if the court treats it as a bar to copyrightability, or the defendant, if the court treats it as a defense to infringement. ${ }^{109}$ Nimmer argues that treating the merger doctrine under the rubric of substantial similarity is the better view. ${ }^{110}$ Finally, Nimmer argues that expert witnesses can provide information to the trier of fact on what constitutes scènes à faire. ${ }^{111}$

Scènes à faire can be a little bit more challenging when applied to musical works. ${ }^{112}$ Should scènes à faire only apply to melody and lyrics, or should it extend to the full panoply of musical elements? One case comments, "[h] aving chosen the familiar theme of a broken-hearted lover seeking solace in country music, the choice of a barroom with a jukebox as the setting in which to unfold this idea simply cannot be attributed to any unique creativity on the part of the songwriter." 13

Additionally, there are limits to the scènes à faire doctrine when applied to music. For example, in Swirsky v. Carey, ${ }^{114}$ the court found that a contested element in a "hip hop/R\&B" song could not be considered as scènes à faire for a folk song. ${ }^{115}$ Furthermore, a musical measure cannot be "common-place" by definition if it is shared by only two songs. ${ }^{116}$

\section{Academic Response to Substantial Similarity and Expert Opinions}

It is clear that the test for copyright infringement is a mishmash of slightly different tests with no underlying consistency. Accordingly, many have criticized the use of "substantial similarity" to determine copyright

\footnotetext{
$107 \quad$ Id. $\S 13.03[\mathrm{~B}][4]$.

108 See Andrew B. Hebl, A Heavy Burden: Property Application of Copyright's Merger and Scènes à Faire Doctrines, 8 WAKE ForeST INTELL. Prop. L.J. 128, 131 (2007).

109 NiMmER, supra note $7, \S 13.03[\mathrm{~B}][3][\mathrm{e}]$.

$110 \quad$ Id.

111 Id. $\S 13.03[\mathrm{E}][3][\mathrm{a}]$ (stating "it is hardly reasonable to expect laymen . . . to delineate the portion of the plaintiff's work that it is protectable" on their own).

112 Torrean Edwards, Scènes à Faire in Music: How an Old Defense Is Maturing, and How It Can Be Improved, 23 MARQ. INTELL. Prop. L. Rev. 105, 109 (2019).

113 Black v. Gosdin, 740 F. Supp. 1288, 1293 (M.D. Tenn. 1990).

114376 F.3d 841 (9th Cir. 2004).

$115 \quad I d$. at 850.

$116 \quad$ Id.
} 
infringement. ${ }^{117}$ A particular problem comes from the analysis of the use of expert opinions, particularly what they should and should not be used for. Additionally, there has been much criticism of the "lay listener test."

Paul Grinvalsky aptly stated that music requires no specialized knowledge to appreciate, but this maxim is not true when comparing two works for infringement. ${ }^{118}$ The "limited language" of music makes even the narrower intended audience test inappropriate. As shown in Figure 1, Grinvalsky argues that music can be viewed as a pyramid divided into four sections. At the base of the pyramid is fundamental similarity (simple characteristics and public domain materials). The next level up is genre (rap, country, classical, heavy metal, etc.). The third level is similarity of ideas (either in sound or on paper) that is based on expert opinion. The top level is substantial similarity with identical works at the apex of the pyramid.

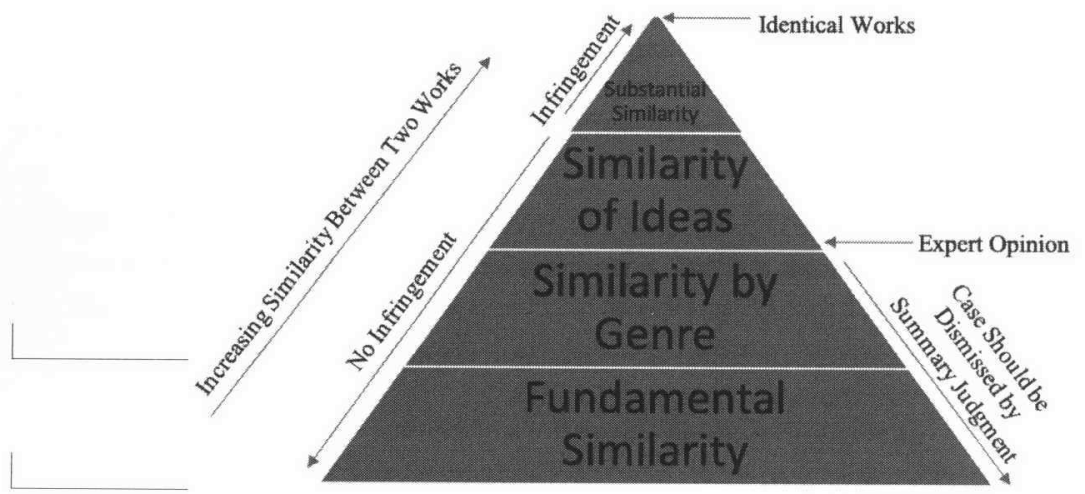

Figure $1^{119}$

Grinvalsky argues that (1) experts should determine if the work falls above or below the similarity of ideas plane and (2) the focal point for the fact finder is to discern if the work falls above or below the plane of substantial similarity. ${ }^{120}$ If the expert finds that there is no similarity of ideas, then the case should be dismissed. Specifically, if the works do not share the same or substantially the same relevant compositional elements, they cannot be objectively similar and thus will fail the extrinsic prong of the Ninth Circuit test and will also fail the

117 See generally Alan Latman, Probative Similarity as Proof of Copying: Toward Dispelling Some Myths in Copyright Infringement, 90 CoLuM. L. REV. 1887 (1990); Lemley, supra note 30; Roodhuyzen, supra note 8.

118 Paul M. Ginvalsky, Idea-Expression in Musical Analysis and the Role of the Intended Audience in Music Copyright Infringement, 28 CAL. W. L. REV. 395, 396 (1991).

119 Adapted from id. at 423.

$120 \quad$ Id. at $422-24$. 
"copying" prong of the Second Circuit test. Only if the work is substantially similar to the reference work will courts impose copyright liability. ${ }^{121}$

Some academics argue that music is unique and that music's complexity "lies beyond any human understanding, which makes the result of an infringement suit unpredictable."122 With regard to musical works, commentators have argued that infringement is based too much on the subjective value of the judge or jury as a proxy for the intended audience of the music. ${ }^{123}$ Additionally, especially with music, it is difficult to draw a distinction between idea and expression. ${ }^{124}$ Accordingly, some courts break a song down into characteristics such as melody, harmony, rhythm, and structure ${ }^{125}$ to help categorize musical technicalities to be used for the similarity analysis. Specifically, Yvette Liebesman has argued that courts should use technology to objectively map a song's artistic elements and use mathematics to model a song. ${ }^{126}$

The "lay listener test" has been shown to create confusion with the jury. ${ }^{127}$ Specifically, jurors have a difficult time distinguishing between the compositional elements in a work and the performance elements of the work. ${ }^{128}$ In fact, at least one jurist has advocated for the use of experts for this second prong of the liability test because lay hearers are incompetent on the issue. ${ }^{129}$ Accordingly, many commentators have suggested the use of expert testimony to mitigate errors for musical works. ${ }^{130}$

$121 \quad$ Id. at $422-23$.

122 Austin Padgett, The Rhetoric of Predictability: Reclaiming the Lay Ear in Music Copyright Infringement Litigation, 7 PIERCE L. REV. 125, 133-34 (2008).

123 Yvette Joy Liebesman, Using Innovative Technologies To Analyze for Similarity Between Musical Works in Copyright Infringement Disputes, 35 AIPLA Q.J. 331, 334-35 (2007).

124 Jeffery Cadwell, Expert Testimony, Scènes à Faire, and Tonal Music: A (Not So) New Test for Infringement, 46 SANTA CLARA L. REV. 137, 157 (2005).

125 John R. Autry, Toward a Definition of Striking Similarity in Infringement Actions for Copyrighted Musical Works, 10 J. INTELL. Prop. L. 113, 121 (2002); see also Tisi v. Patrick, 97 F. Supp. 2d 539, 539 (S.D.N.Y. 2000); Paul J. Heald, Reviving the Rhetoric of the Public Interest: Choir Directors, Copy Machines, and New Arrangements of Public Domain Music, 46 DUKE L.J. 241,258 (1996).

126 Liebesman, supra note 123.

127 Jamie Lund, An Empirical Examination of the Lay Listener Test in Music Composition Copyright Infringement, 11 VA. SPORTS \& ENT. L.J. 138, 160 (2011).

$128 \quad$ Id.

129 Arnstein v. Porter, 154 F.2d 464, 476-77 (2d Cir. 1946) (Clark, J., dissenting).

130 E.g., Cadwell, supra note 124, at 162-63; Amy B. Cohen, Masking Copyright Decisionmaking: The Meaninglessness of Substantial Similarity, 20 U.C. DAVIS L. REV. 719, 766 (1987); Alice J. Kim, Expert Testimony and Substantial Similarity: Facing the Music in (Music) Copyright Infringement Cases, 19 ColUM.-VLA J.L.\& ARTs 109, 112 (1994); Lemley, supra note 30 , at $740-41$. 
Mark Lemley argues that the basic analysis for copyright infringement is exactly backwards. Specifically, he argues that experts will usually not be needed for the "extrinsic" 131 or "copying"132 stage of the copyright infringement analysis. ${ }^{133}$ This is because the basic question that is asked at this step is, "does the similarity between the two works lead you to believe that the defendant must have copied from the plaintiff?"134 Lemley then argues that expert testimony is also required for the second prong of the infringement inquiry, whether the defendant copied more than a de minimis amount that was copyright protected. ${ }^{135}$ In fact, other commentators have argued that expert testimony is limited, or even prohibited, where it is most needed - at the improper appropriation prong. ${ }^{136}$ The problems associated with lack of expert testimony on the second infringement prong are as follows: (1) expert testimony helps juries determine if the taking of material was illegal, (2) expert testimony helps educate juries on the difference between protectable and unprotectable elements, and (3) a jury-decided "ordinary observer" test is not easily open to judicial review. ${ }^{137}$ Accordingly, Lemley suggests (1) reversing the "intrinsic" and "extrinsic" components of the test to allow for expert testimony "intrinsic" analysis; ${ }^{138}$ (2) allowing expert testimony in both prongs, ${ }^{139}$ or (3) making the ultimate determination of infringement (Prong 2) a question of law rather than a question of fact. ${ }^{140}$

\section{BASICS OF MACHINE LEARNING}

Simply stated, machine learning is the subset of AI which provides machines the ability to learn and improve from the experience without being explicitly programmed. There are two relevant types of machine learning: (1) supervised learning and (2) unsupervised learning.

\footnotetext{
131 See supra notes 37-40 and accompanying text.

132 See id.

133 Lemley, supra note 30, at 737 (stating that “probative similarity doesn't seem a logical place to employ expert testimony [but] experts may be necessary to assess basic questions of similarity with complex technologies like software ... [and] expert testimony can be useful where the issue is one of merger or scènes à faire").

$134 \quad I d$.

$135 I d$.

136 Cadwell, supra note 124 , at 158.

137 Lemley, supra note 30, at 738-39.

138 See Kim, supra note 130 , at $120-21$.

139 See id. at 122 (arguing that "expert testimony should be admitted for the benefit of the trier of fact, at every step of the analysis").

140 Lemley, supra note 30 , at $738-40$.
} 


\section{A. Supervised Learning}

The goal of supervised learning is to forecast outcomes. The method by which supervised learning works is by guidance from labeled input to known output. With supervised learning, the algorithm is trained ex ante by giving it data with known results. Thus, the training data contains labeled input as well as labeled output. Thus, the training data acts as a mentor or a teacher for the algorithm.

Teaching through supervised learning is accomplished through multiple steps. First, the training data includes as many examples as possible of the thing you are trying to teach. Second, there is a choice of architecture for learning the model (e.g., classic neural networks, convolutional neural networks, or recurrent neural networks). Third, creation of a penalty (loss function) that the algorithm uses to determine the magnitude of an erroneous decision, and thus learn how to be more correct the next time (i.e., performance measurement). Finally, the mechanisms using technologies, such as Stochastic Gradient Descent (SGD) and then Backpropagation, are updated.

During the training phase, the algorithm will map the known input to the known output to validate the data. Once the machine is trained, it will be given a new set of unlabeled "real world" data that it can then classify based on its previous training. Thus, when the machine labels "real world" data, it creates an inference between the data and the classified outcome. Typically, supervised learning is used to address regression or classification problems.

In the musical infringement context, a set of experts could create a "training dataset" by reviewing a set of songs and labeling the songs as "similar" or "not similar." This could be done using previously litigated music cases as well as songs that have not been reviewed by a court. The "training dataset" is then given to the algorithm to learn which songs are similar or not similar. To train the algorithm with a positive dataset, songs that were licensed ${ }^{141}$ and unlicensed songs that were found to infringe or subsequently licensed ${ }^{142}$ could be included. To train the algorithm with a negative dataset, songs that were unlicensed and found not infringing could be included. Furthermore, crowdsourced websites, such as whosampled.com, create databases of songs that are sampled, covered, or remixed. ${ }^{143}$

The algorithm would learn from this training dataset so that it would then be able to forecast an outcome from a new set of inputs. Under supervised

141 Licensed songs would be included because the second author would be conceding similarity thereby securing a license.

142 E.g., Ben Sisario, Tom Petty To Share Credit for Sam Smith's "Stay With Me", N.Y. TIMES (Jan. 25, 2015), https://artsbeat.blogs.nytimes.com/2015/01/26/tom-petty-to-share-credit-for-samsmiths-stay-with-me/.

143 See About US, WhoSAMPLED, https://www.whosampled.com/about/ (last visited Feb. 20, 2021). 
learning models, the algorithm will be either able to: (1) classify the song as "similar" or "not similar" (binary decision) and/or (2) use regression to determine how similar two songs are to each other (e.g., under a regression analysis the machine could state that song one was $85 \%$ similar to song two). ${ }^{144}$

\section{B. Unsupervised Learning}

The goal of unsupervised learning is to discover underlying patterns and extract useful insights. Unsupervised learning works by giving the algorithm a set of unlabeled inputs and allowing the algorithm to explore any patterns and trends it finds to create a set of correlations essentially on its own. With unsupervised learning, the algorithm is trained on unlabeled data without any guidance and has to learn the output on its own. The algorithm will simply group items with similar characteristics together, finding patterns and trends between the datasets. This type of learning can be used to solve association and clustering problems.

In the musical infringement context, the algorithm would be given a set of paired songs, and it would have to look for patterns and trends between the songs to determine if a song is "similar" or "not similar" to another song. Clustering can be used to help classify songs into specific genres. ${ }^{145}$ Unsupervised learning would also reveal associations between songs such as which riffs or sets of notes are scènes à faire and which notes are copyrightable expression. The algorithm would not need to be explicitly told which specific notes to compare but would be able to detect problematic similarities on its own, thus ensuring an even more comprehensive review than is typically possible with lay observers.

\section{USE OF ARTIFICIAL INTELLIGENCE IN THE CURRENT COPYRIGHT INFRINGEMENT FRAMEWORK}

This Article argues for both a different type of expert witness as well as a different role for this special type of expert witness. AI could fill the role of not only an impartial expert witness for the first prong of the infringement analysis but could also be used as an "ordinary AI observer" for the second prong of the infringement analysis. When used for both prongs of the infringement analysis, AI has the ability to become a powerful tool to help determine copyright infringement for musical works.

Two different types of algorithm learning would be needed for the two different prongs of the infringement analysis. Specifically, unsupervised learning could be used for the first "extrinsic" or "copying" prong, while supervised learning could be used for the second "intrinsic" or "unlawful appropriation"

\footnotetext{
144 See infra Section 0.C.

145 See infra Section 0.B.
} 
prong. Below, this Article discusses the general principles that could be used for the AI framework as well as specific costs and benefits associated with the use of AI for each prong of the copyright infringement analysis.

\section{A. General Principles-Use of Standard Algorithms for Each Prong of the Infringement Analysis}

At the heart of all AI decision-making are the algorithms. These algorithms are created by the data and can include not only the traditional artistic elements of a song, such as melody, harmony, rhythm, and structure, but also elements of mathematical models as suggested by Liebesman. ${ }^{146}$ Additionally, rather than follow only explicitly programmed instructions, some algorithms would allow the machines to learn on their own. ${ }^{147}$

If the algorithm is just the starting point and the AI is allowed to "learn," then there would be less need to create multiple algorithms to deal with nonconforming situations. Musicians, music theoreticians, composers, musicologists, and forensic musicologists could come together to work out the elements needed to create a robust standard algorithm that could determine those elements of music that were simply scènes à faire and other non-protectable elements. These conversations could also include experts in music copyright as well as AI engineers to help fashion the algorithm for use in the legal context. The AI could also use a large library of songs to help refine the algorithm in a meaningful fashion. Additionally, as musical genres change and grow, so too could the algorithm. Different elements of songs may move from copyright protectable to unprotectable functional material or scènes à faire as more and more musicians use those riffs or a new genre of music is created. The algorithm could capture this change over time to help determine which elements are copyright protectable versus unprotectable.

If there is one set of weights and measures by which most experts can agree to create the algorithm, this standard algorithm could create consistency in an otherwise sea of inconsistent analyses. Creating a standard algorithm has many advantages in that multiple genres could be analyzed at once and no song would be excluded from analysis. However, some genres of music may have characteristics that bend the algorithm to the point where a standard algorithm may not work. ${ }^{148}$ If that is the case, then perhaps using separate algorithms for this specific genre would create stability and consistency of analysis for copyright infringement of musical works. The problem with using multiple

\footnotetext{
146 See generally Liebesman, supra note 123.

147 See supra Part 0.
}

148 For example, neural networks can easily classify classical music while jazz music presents the most difficulty. See Muralidhar Talaupur, Suman Nath \& Hong Yan, Classification of Music Genre, Project Report for 15781, CARNEGIE MELlon UNIV., http://www.cs.cmu.edu/ yh/files/GCfA.pdf (last visited Feb. 20, 2021). 
algorithms for different genres would be that it would be more difficult to compare works that cross different genres or works that straddle multiple genres. ${ }^{149}$

There would be tremendous advantages to the industry if a standard algorithm could be agreed upon. This could be modeled upon the same standardsetting organizations that created Reasonable and Non-Discriminatory terms or Fair, Reasonable, and Non-Discriminatory terms for holders of standardessential patents. Furthermore, groups such as the Recording Industry Association of America ("RIAA") and Broadcast Music, Inc. ("BMI"), have played a pivotal role as agents of change in copyright law's evolution when it comes to the music industry. Because RIAA members create, manufacture, or distribute "nearly $85 \%$ of all legitimate recoded music produced and sold in the United States" and BMI licenses approximately " 15 million musical works," these industry groups could easily help create this industry standard. ${ }^{150}$ In fact, the RIAA has already created standards in music, such as creating technical standards ${ }^{151}$ and creating the Parental Advisory Label. ${ }^{152}$ Accordingly, setting standards in the music industry may be easier than setting standards in other industries which may not have such concentrated and powerful industry groups.

\section{B. Use of Unsupervised Learning Algorithms as an Expert for "Extrinsic Analysis" and "Copying" of Musical Works}

In many ways, the use of $\mathrm{AI}$ as an expert witness for the first prong of the copyright infringement analysis is not a revolutionary proposal. This is because many circuits already use expert testimony to help the jury determine if there was unlawful copying. ${ }^{153}$ Thus, AI could be used in two different ways for the first prong of the "extrinsic" or "copying" step. First, AI could simply be used as a tool to help the court dissect the work and determine if there is a "similarity

\footnotetext{
149 E.g., Campbell v. Acuff-Rose Music, Inc., 510 U.S. 569, 599 (1994) (where 2 Live Crew's rap version of "Pretty Woman" was found to be fair use of Roy Orbison's country/rock song "Oh, Pretty Woman"); see also Copeland v. Bieber, 789 F.3d 484, 492-93 (4th Cir. 2015).

150 About RLAA, RECORDING INDUS. AsS'N OF AM., http://www.riaa.com/about-riaa/music-orgs/ (last visited Feb. 22, 2021); About, BROADCAST MUSIC, INC., http://bmi.com/about (last visited Feb. 22, 2021).

151 Resources \& Learning, RECORDING INDUS. Ass'N OF AM., http://www.riaa.com/resourceslearning/technical-standards/ (last visited Feb. 22, 2021) (stating that the RIAA participated in creating standards such as the Global Release Identifier ("GRid"), Digital Data Exchange, Watermark Payload Specification, the International Standard Recording Code ("ISRC"), and DualDisc).

152 Parental Advisory Label, RECORDING INDUS. Ass'N OF AM., https://www.riaa.com/resources-learning/parental-advisory-label/ (last visited Feb. 28, 2021) (the RIAA worked with the National Parent Teacher Association and the Parents Music Resource Center to create this standard to address issues regarding explicit content in sound recordings).

153 See, e.g., Walker v. Time Life Films, Inc., 784 F.2d 44, 51 (2d Cir. 1986).
} 
of ideas" between the two works. Second, AI could dissect the reference work in a fashion where the non-copyrightable portions of the reference work are extracted and only the expressive portions of the work are shown to the trier of fact. These expressive portions of the reference works could be shown side by side against the allegedly infringing work.

\section{Algorithm as an Expert Witness}

AI could be used in this first prong much like current expert witnesses are being used. Specifically, the algorithm could be used to simply compare two works and help determine which portions of the work are "copied." The algorithm could be used to do the work that is currently done by forensic musicologists and determine similar parts, transcribe those parts, transpose them into the same key for ease of comparison, and then examine melodic, harmonic, lyric, rhythmic, and structural elements. The algorithm would do this in a manner consistent with the formula agreed upon by an industry standard. In many ways, AI would simply be automating what is currently done by experts, and thus, it would be slightly more impartial.

The algorithm would then determine which sections of the referenced works were scènes à faire, motifs, or commonplace building blocks of music that fall outside the scope of copyright protection. If the algorithm finds that there is no similarity of ideas between the two works, the court could simply dismiss the case at an early stage, saving litigants both time and money. Furthermore, if there is a standard algorithm that is an industry standard, then the potential infringer could run the AI ex ante to either change the work to avoid infringement issues or run the risk of copyright infringement. Additionally, if there is great risk of infringement, then the potential infringer could use the structured learning algorithm to gauge the potential for unlawful copying. ${ }^{154}$

This system, however, would not work well if both litigants insisted upon their own algorithm. If both litigants required the parameters of the algorithm to be altered in significant and conflicting ways, the courts could end up with a "battle of the algorithms," which is one of the major drawbacks associated with the current framework for the first prong of copyright litigation.

Furthermore, this system could act as a check against litigation. Specifically, if an alleged infringer did not run the algorithm against a database of songs, then courts could impose enhanced damages such as willful infringement under 17 U.S.C. $§ 504(c)$. 
2. Use of Machine Learning to Create a Scènes à Faire/Functional Harmony Library

The extrinsic or copying prong of copyright infringement requires the court to dissect the work to determine which portions of the work contain protectable expression versus those portions of the work that are not copyright protectable. Algorithms based on unsupervised learning are best suited to address these types of problems. The algorithm could be given a large set of songs and determine which portions are common to many songs. Ideally, songs would be fractured into 10 to 15 second riffs. The algorithm would then use the unlabeled data to determine which riffs had common elements and could cluster the data into relevant groups. If certain riffs or certain patterns are found in many different songs, then those portions may be considered functional ${ }^{155}$ or part of the scènes à faire.

Currently, when songs are litigated, the two songs are compared against each other, and the court relies on expert witnesses and their vast knowledge of music and music theory to determine which portions of the song are open to all and those portions which are unique and expressive. ${ }^{156}$ Use of unstructured learning with an industry standard algorithm would create a library of riffs that could be categorized as scènes à faire or functional if found in enough songs that are in the public domain. This would give litigants the knowledge ex ante to determine if their songs contained protectable material or material that could be infringing.

Furthermore, using unstructured learning to create a library of scènes à faire riffs can act as an escape valve so that music could evolve and adapt moving forward by allowing musicians to use key riffs that define a genre. For example, in Year 1, the AI might find that a piece of innovative music created by Artist X should be protected because many portions of her song are unique and expressive and help create a new genre of music. As those riffs become popular, in Year 20, the AI might find many of those same riffs being used by many other artists (artists would be forced to license those riffs during the development stage of the genre). However, when the genre is better developed in Year 21, those riffs may be now part of the scènes à faire and free for other artists to use. Accordingly, the original would benefit from a required license for those first 20 years, but then would lose copyright protection after those riffs become part of the scènes a faire. However, note that this is not an unfamiliar concept, as this forfeiture occurs in trademark law as "generic" marks. ${ }^{157}$ Thus, similar to a trademark that

\footnotetext{
155 Gherman, supra note 31, at 489.

156 See, e.g., Walker, 784 F.2d at 51.

157 A generic mark is a word that is understood by the public as the common term for a product or service. Thus, if the primary significance of the mark to the relevant public refers to the class or category of goods, then the term is generic. Examples include: "Band-Aid" for adhesive bandage, "Kleenex" for facial tissue, or "Xerox" for photocopier.
} 
becomes generic, a copyrighted riff that becomes widely successful may lose protection via the scènes à faire doctrine. This would allow the original artist to monetize the work early in the copyright lifecycle, while not stifling innovation of expression for long periods of time.

As mentioned in Section IV.A. above, the AI would be based on an algorithm that would have the benefit of a large library of songs to help refine the results. Alternatively, if litigators wanted to limit the universe of comparisons, they could simply narrow the genre or type or specific songs that would be used to "train" the AI. Accordingly, this Article suggests use of one standard algorithm that could capture patterns from all types of music. Thus, unstructured training could be based on a variety of different works so that common associations and clusters could be mapped based on all musical works and not just specific genres. Alternatively, the court could force the litigants to agree upon one algorithm to be used by both parties, similar to forcing both parties to choose one common expert.

To implement this system, you could piggyback off of a large music provider, such as Spotify or Pandora. After listening to two song clips (no more than 15-30 seconds), the application would first ask users to determine if the two song clips were similar to each other. The application would then ask the listener a set of "deeper questions," such as what elements of the clips made them similar. The application would walk the listener through a longer set of questions to determine if the song's melody, harmony, rhythm, pitch, tempo, phrasing, structure, chord progressions, lyrics, timbre, tone, spatial organization, consonance, dissonance, accents, note choice, combinations, interplay of instruments, or basslines influenced the user's decision to mark the works similar or dissimilar. "High scoring" users (users who score similar to musicologists and other traditional experts) would be placed in an "expert group" to help guide the AI's extrinsic analysis. In essence, these expert group users would be (1) verifying the classifications generated by the algorithm and (2) helping to create labeled data for the second "intrinsic/unlawful copying" prong of the test. This type of analysis would help address the problems associated with the lay listener test. $^{158}$

One problem with machine learning is that most machine learning systems do not combine reasoning with calculations. ${ }^{159}$ AI systems that are based only on unsupervised learning will simply construct a set of correlations whether they make sense or not. Accordingly, by adding reasoning to machine learning systems (in the form of human verification by an "expert group"), these correlations and insights can become much more useful. Thus, verification of

\footnotetext{
158 Lund, supra note 127.

159 Stephen F. Deangelis, Artifical Intelligence: How Algorithms Make Systems Smart, WIRED, https://www.wired.com/insights/2014/09/artificial-intelligence-algorithms-2/ (last visited Apr. 5, 2021).
} 
specific riffs as "similar" or "not similar" by an "expert group" would help validate the correlations established by the algorithm.

\section{Use of Structured Learning Algorithms for "Intrinsic Analysis" and "Unlawful Appropriation"}

Interestingly, AI can become "smarter" at distinguishing between not only genres of music but what the intended audience deems substantially similar. You can imagine using an application such as Spotify or Pandora to simply ask its user to rank the similarity between the current and previous song or song excerpt. When possible, the program should exclude those portions of the song or excerpt that was deemed to be scènes à faire or functional (as determined by prong one of the infringement test). The algorithm could generate a "similarity score" as the AI becomes better at distinguishing the nuances between different songs in the same genre based on input from actual consumers (the intended audience).

Creating a standard training dataset that most experts could agree upon would make the supervised learning step for intrinsic analysis more consistent and more transparent. The results would be more consistent than our current framework because the algorithm would apply the same formula and learn based on every song used in the training data. Additionally, the results would be more transparent because all parties would be able to examine and investigate the algorithm and training data for any possible flaws. Furthermore, the algorithm could be verified using data from the "expert group" of users as identified in the "extrinsic" step. Alternatively, the algorithm could actually use the labeled data from the "expert group" to help improve the supervised learning step. If done on a large scale, the algorithm will become adept at not only classification of music as "similar" or "not similar" but also at creation of a regression for infringement (the algorithm could tell the potential infringer that the work is $80 \%$ similar or $95 \%$ similar to the protected portion of the referenced work).

Similar to the implementation above, you could use the "intended audience" users in the lay listener group to help with the intrinsic test. Average users may not answer the "deeper questions" but only answer the "is it similar or not" question. Additionally, you could determine the genres of music associated with each user, thereby creating an "intended audience" database. By simply tracking the number of hours of listening to a specific genre of songs, the application could code each user as a "lay listener" of a specific genre of music. By creating this cohort of "lay listeners," you could then ask them questions regarding substantial similarity by sharing the edited versions of the song where the common elements (as determined by the algorithm in the first prong) were removed. Accordingly, the "lay listeners" or "intended audience members" should not be influenced by those elements that are common or functional to all songs, especially if they listen to only one genre of music. This type of structured 
learning, however, may not address the inherent confusion many lay listeners have with musical works. ${ }^{160}$

An additional advantage of using an algorithm for the "intrinsic/unlawful copying" prong is that the algorithm not only classifies the data but gives a regression. Specifically, with a regression, you could create a sliding royalty rate. For example, two potentially infringing songs are run through the algorithm. The algorithm (with "expert group" verification) determines that song one has a $60 \%$ similarity score when compared to the protected elements of the referenced work. In contrast, the algorithm determines that song two has a $95 \%$ similarity score when compared to the same referenced work. The owners of the referenced work could then charge more to the author of song two when compared to the author of song one. Additionally, it would allow the author of song one ex ante to determine whether it is worth the risk to go ahead without licensing with the owner of the referenced work. If courts or legislatures could come up with a numerical cutoff for substantial similarity, then all authors could know their risk of copyright infringement before engaging in costly marketing and distribution of a song.

This system would shift the nature of copyright liability for both songwriters and producers. Songwriters could ex ante determine if their songs are "too similar" and thus should be changed or risk litigation. In contrast, if the algorithm determined the songs to be "not similar," songwriters could then keep their expressive work the way it was originally written, thereby promoting the "progress of science and the useful arts." Additionally, producers and record labels would no longer have to purchase high priced liability insurance to protect against unlawful copying because they would know the risk of infringement ex ante and either force the songwriter to change the song or face possible liability. Hopefully, this savings would be passed along to the consumer in both a higher volume of expressive works as well as lower prices for music.

\section{Social Benefits Associated with Using AI to Determine Copyright Infringement}

\section{Notice Function of Copyrights}

There are several key benefits associated with the use of AI to help determine copyright infringement. The first benefit is related to the notice function of copyrights. Patent law has long recognized the importance of notice to downstream inventors. ${ }^{161}$ Through the use of patent claims, inventors attempt to give notice to the world of the scope of their rights. Use of AI could serve a similar function by giving musicians some general guidance as to what may or

\footnotetext{
$160 \quad I d$.

161 Duncan Parking Techs., Inc. v. IPS Grp., Inc., 914 F.3d 1347 (Fed. Cir. 2019) (stating that "the public has a right to rely on the language of patent claims").
} 
may not be infringing before they go through the costly exercise of production and distribution of the musical work.

The current ex post nature of the substantial similarity regime puts smaller, unestablished, undercapitalized artists at a severe disadvantage against well-capitalized record labels which can aggressively litigate alleged infringement. ${ }^{162}$ Although Joseph Fishman focuses on the melody of musical works, he looks at infringement through the lens of facilitation of downstream composers' future creativity. ${ }^{163}$ Use of AI could address two major issues associated with the notice function needed for copyrights. First, it would give artists the ability ex ante to predict whether their work infringes the prior work. Second, it would help establish the boundaries of the owners' entitlements the moment they were created, instead of establishing them through costly litigation. first and then

The current substantial similarity test requires most musicians to create

wait to see if litigation ensues. Even if an author knows that his work shares some features with an earlier sound recording, there is no instinctive means by which that author can predict whether the similarity between the two works will be regarded as excessive, and result in an infringement judgment. ${ }^{164}$

As previous commentators have acknowledged, jurors have a difficult time distinguishing infringement of the composition versus the sound recording. ${ }^{165}$ Because AI determinations should be more consistent compared to jury verdicts, future artists could ex ante determine if they have borrowed "too much." Additionally, because the algorithm would be trained by music experts, the algorithm should not be "fooled" by changes in elements such as timbre, orchestration, tempo, key, and style. Thus, the use of AI would allow musicians to test first and either change the work or accept the risk if the algorithm found the new work to be "too similar" to the prior work.

\section{Valuation}

Another benefit associated with the use of AI is the fact that it could adjust copyright scope based in time. The algorithm would be constantly taking in new information and incorporating new musical works. Consequently, as a work gets older, the algorithm might find new patterns that were not previously present. For example, if a new work comes out that establishes a new genre of music, it could be found copyrightable when it initially came out and given a

\footnotetext{
162 David Fagundes, Crystals in the Public Domain, 50 B.C. L. REv. 139, 159 (2009).

163 Fishman, supra note 12, at 1870.

164 Fagundes, supra note 162, at 158.

165 Lund, supra note 127.
} 
wide scope of copyright protection. However, as time progresses and more artists build upon the foundation set by the first artist, those musical elements that were initially copyrightable may now be included as scènes à faire. Other commentators have already proposed narrowing copyright scope based on time. ${ }^{166}$ However, these commentators use fair use to narrow the scope of the copyrighted work. Specifically, these commentators argue that the older a copyrighted work is, the greater the scope of fair use. ${ }^{167}$ In contrast, AI has the ability to achieve the same result based on using the scènes à faire/merger doctrine to negate substantial similarity. Use of AI is particularly amenable because, as some commentators argue, the technical opinion of experts should be heavily relied upon when applying the scènes à faire doctrine. ${ }^{168}$

\section{Transparency}

Transparency is another major advantage of using machine learning for musical copyrights. Transparency in the algorithm code used for unstructured and structured training allows for all parties to investigate the potential strengths and flaws of the machine learning algorithm. For example, in the context of unstructured learning, if a musical work contains a unique element that was not taken into account by the standard algorithm, then, under extreme circumstances, the algorithm or training data could be modified to account for the unique issue. Alternatively, if there is a genre of musical works that faces the same issues, a different set of training data could be used for those works so that the algorithm can better account for these specific issues. In the context of structured training, transparency can occur at two levels: (1) the algorithmic level which is open for all to examine and (2) the training level, where all the training data could be open for examination.

Previous commentators have noted that transparency of algorithmic systems can be lacking for many reasons. ${ }^{169}$ Some may argue that AI does not make the process any more transparent because the choices made by software engineers and algorithms may be just as confusing as choices made by a jury. However, advances in AI, such as Explainable AI ("XAI"), have created a suite of machine learning techniques that produce more explainable models while

166 Justin Hughes, Fair Use Across Time, 50 UCLA L. Rev. 775, 799 (2003); Joseph P. Liu, Copyright and Time: A Proposal, $101 \mathrm{MICH}$. L. REv. 409, 412 (2002).

167 Liu, supra note 166 , at 410.

168 Edwards, supra note 112, at 116.

169 Burk, supra note 16, at 301 (stating that transparency is difficult for algorithms because: (1) of intentional obscurity due to attempted protection of confidential business information, (2) of the esoteric nature of the technology, which requires technical expertise, and (3) even experts are unlikely to understand how an algorithm operates even if it is open to inspection). This article argues that programs, such as XAI, can help with the esoteric nature of the technology and experts understand the operation of the algorithm. However, XAI, and all algorithms, cannot address the issues associated with intentional obscurity. 
maintaining a high level of learning and prediction accuracy; advances also enable users to understand, trust, and effectively manage the algorithms. ${ }^{170}$ Matt Turek argues that "these new machine learning systems have the ability to explain their rationale and characterize their strengths and weaknesses to convey how they might behave in the future." not be created only by software engineers, but in concert with all stakeholders such as musicians, producers, musicologists, copyright experts, and AI engineers.

\section{Move Control Back to the Creator}

Henning Grosse Ruse-Khan noted that platforms such as Facebook and YouTube act as "functional sovereigns" in that they create rules, apply those rules, enforce them, and also act as adjudicators over those disputes. ${ }^{172}$ Using automated tools, such as Content $\mathrm{DD}$, these platforms wield far-reaching copyright powers that dramatically alter the copyright policy created by legislators. Although individuals who use these platforms validly agreed to the rules set forth by those platforms, it is doubtful that "notions of party autonomy and freedom of contract were designed to serve as foundations for creating private content protection regimes with global reach, pared with immediate and automated enforcement."173 Accordingly, these functional sovereigns have moved copyright law from a public law framework (designed by numerous stakeholders) to a private law framework (designed for monetization and risk minimization), thereby upsetting the delicate normative balances set forth by legislators. The framework in which these platforms police and enforce copyrights are currently (and somewhat unsurprisingly) heavily biased in favor of the referenced work owner's claim. In fact, once Content ID flags the material as possibly infringing, the referenced work owner is "responsible for avoiding incorrect results," such as "claims that result from misidentified content or claims that interfere with authorized uses of content." "174

By forcing private actors such as Facebook and YouTube to recognize a publicly created standard algorithm, we could help bring back a modicum of public control over music copyrights. A similar possible solution would be for platforms to simply add the use of a publicly created standard algorithm after

170 David Gunning \& David W. Aha, DARPA's Explainable Artificial Intelligence Program, 40 AI MAG. 44 (2019).

171 Matt Turek, Explainable Artificial Intelligence (XA1), DEF. ADVANCE RSCH. ProJECTS AGENCY, https://www.darpa.mil/program/explainable-artificial-intelligence (last visited Mar. 19, 2021).

172 Ruse-Khan, supra note 16, at 9.

$173 \quad I d$.

174 Content for Content ID, YouTuBE HeLP, https://support.google.com/youtube/answer/2605065 (last visited Feb. 28, 2021). 
they run their own automated copyright enforcement programs. If the standard algorithm does not find the work infringing on a reference work, then the burden of proof for infringement would shift to the reference work owner to show infringement. This framework would allow platforms to avail themselves of the Digital Millennium Copyright Act safe harbor while shifting the default burdens and presumptions against the prior-work owner. Alternatively, platforms could simply replace their current enforcement programs, at least for musical works, with an industry-standard algorithm.

5. Allows for Multidimensional Analysis Without Loss of Notice Function

Fishman argues for a unidimensional analysis using melody as the hallmark to help determine if copyright infringement has occurred in a musical work. ${ }^{175}$ One cost associated with this proposal is that composers who know that a melody carries enhanced copyright protection will "rationally focus more on writing unappropriable tunes than on other, easily appropriable forms of musical expression." 176 The benefit of this system would be increased consistency in litigation and better notice to future artists of what is covered and not covered by copyright. This loss of expression, however, is especially troubling since in many types of popular music, such as the $\$ 7$ billion electronic dance music industry or the harmonic and rhythmic innovations of artists of color, ${ }^{177}$ artists rely not on melody but on production of the underlying beats and harmonies (while melody is "frequently the last thing to be ironed out"). ${ }^{178}$ Using AI would allow for artists to have their cake and eat it too. AI would allow for copyright protection not only through an analysis of melody but also through a multidimensional analysis of many elements associated with music. Accordingly, artists would not have to engage in gamesmanship to create works that focus primarily on melody. Additionally, it would give downstream, future artists the legal predictability necessary to dispel their fears about copying a melody while changing many other elements of the musical work. Accordingly, use of AI allows musicians to focus on creating novel expression (regardless of if they copy the melody) while giving them ex ante notice of possible copyright issues.

\footnotetext{
175 Fishman, supra note 12.

$176 \quad$ Id. at 1913.

177 See Olufunmilayo B. Arewa, Blues Lives: Promise and Perils of Musical Copyright, 27 Cardozo ArTs \& EnT. L.J. 573, 592 (2010); Olufunmilayo B. Arewa, From J. C. Bach to Hip Hop: Musical Borrowing, Copyright and Cultural Context, 84 N.C. L. REV. 547, 625-28 (2006).

178 Fishman, supra note 12, at 1899-901.
} 


\section{Consistent Application of Inputs}

Age-related hearing loss (prebycusis) is common and gradually occurs when we get older. ${ }^{179}$ Approximately one in three people in the United States between 65 and 74 has some form of hearing loss. ${ }^{180}$ Usually, age-related hearing loss occurs in both ears, affecting them equally. Additionally, because loss is gradual, many people do not even realize that they have lost some ability to hear. ${ }^{181}$

Accordingly, some jury members, as well as expert witnesses, may not be able to hear the sounds presented in an audio version of the musical work. These problems are not present when using AI to review sound recordings. Because a computer suffers no hearing issues and is able to compare musical works using a purely digital format, there is no bias created by hearing loss.

\section{E. Social Costs Associated with Using AI To Determine Copyright Infringement}

The first concern with AI deals with a problem that is associated with all algorithms, which is that they are created by humans with all of the human errors and biases. As with all algorithms, the data must be collected, processed, analyzed, and evaluated by experts. Accordingly, the algorithm will necessarily be biased by those who create them. Design choices for elements to be included in the algorithm must be made, and subsequent weights must be given to these specific elements. Each of these decisions will be the product of a human decision, and thus the algorithm will be inherently biased by those human decisions. This problem is associated with all algorithms not just those associated with determining copyright infringement. This problem may be minimized, however, by creating a standard that can be agreed upon by musicians, music theorists, copyright experts, and the engineers who code the algorithm. Additionally, by using learning models that piggyback on products like Spotify and Pandora, you could imagine the algorithm being able to "learn" quickly and hopefully in a less biased manner.

Another significant cost of using AI to determine copyright infringement would be the role of fair use. Dan Burk and Matthew Sag have discussed issues associated with copyright enforcement algorithms and have shown that the "take down" discussion, when it comes to digital platforms, initially does not take into account fair use analysis. ${ }^{182}$ Accordingly, the removal of online content may be "final before the dispute reaches any forum in which defenses such as fair use

\footnotetext{
179 Age-Related Hearing Loss, Nat'L InSt. on Deafness \& OTHER COMmC'N Disorders, https://www.nidcd.nih.gov/health/age-related-hearing-loss (last visited Mar. 6, 2021).

$180 \quad$ Id.

181 Id.

182 Burk, supra note 16 , at 283 ; Sag, supra note 16 , at $543-44$..
} 
might be considered." ${ }^{83}$ In fact, Burk and Julie Cohen argue that fair use cannot be programmed into these algorithms and that a fair use analysis will always need human oversight or institutional infrastructure. ${ }^{184}$

As an initial matter, it is important to note that the fair use doctrine may not be a major issue when it comes to musical works. Despite the relatively high number of music cases decided under the 1976 Copyright Act, no decision has held that copying musical notes or elements is fair use, and very few cases have even considered fair use. ${ }^{185}$ Additionally, one factor in the fair use analysis is transformative use/purpose. It is difficult to determine if incorporating someone else's music into a song "adds something new, with a further purpose or different character, altering the first [work] with new expression, meaning, or message." 186 Case law dealing with transformative use of musical works mainly focuses on the transformative purpose of the music, which is "more contestable or difficult to describe in the case of a musical work borrowing from another musical work." ${ }^{87}$ Accordingly, this fair use issue may be less of a problem for musical works compared to other copyrightable subject matter.

One possible solution, however, to the fair use issue is to use AI only to help determine validity of the prima facie case for copyright infringement. After this initial step, then the trier of fact could consider copyright infringement defenses such as fair use. This combination of formal rules with accommodating standards will allow for economies of scale while minimizing problems caused by unforeseen circumstances and the individualized circumstances of unauthorized use. ${ }^{188}$

Expanding the use of AI to determine copyright liability for subject matter outside of musical works may not be appropriate. Musical works may be more amenable to this type of automated analysis because there are a finite number of notes and a limited number of notes and chords that are available to composers that are consonant. As Fishman noted, when it comes to melody, "[its] modularity and quantifiability enables second comers to make a reasonable $e x$

\section{Burk, supra note 16, at 290.}

184 Dan Burk \& Julie Cohen, Fair Use Infrastructure for Rights Management Systems, 15 HARV. J.L. \& TECH. 41, 55-58 (2001) (stating that "[b]uilding the range of possible uses and outcomes into computer code would require both a bewildering degree of complexity and an impossible level of prescience"); see also Burk, supra note 16, at 291 (stating that "[p]rominent computer scientists similarly expressed their deep skepticism that fair use could be programmed into a technical system").

185 Lee, supra note 4, at 1874, 1900 (showing that $91 \%$ of the cases reviewed did not discuss fair use at all and most cases resulted in a finding of no infringement or liability against the defendants and concluding "the fair use defense was unnecessary for music defendants to prevail").

186 See id. at 1920 (citing Campbell v. Acuff-Rose Music, Inc., 510 U.S. 569, 579 (1994)).

187 Id.

188 See generally Burk, supra note 16, at 297; Louis Kaplow, Rules Versus Standards: An Economic Analysis, 42 DuKE L.J. 557, 575-76 (1992). 
ante guess as to whether they have taken too much." 189 This is in contrast to attempting to reduce the dramatic plot of a play or a movie into a scientific formula, which may be impossible to do ${ }^{190}$ Furthermore, music may rely more heavily on expert testimony than other copyrightable subject matter. ${ }^{191}$ Additionally, fair use has customarily played a diminished role when it comes to musical works. Moreover, AI may be better suited to determine common themes and genres found in music than in other copyrightable subject matter, such as pictorial or literary works. For example, it may be easier for an AI algorithm to determine a common set of chords and melodies associated with blues music than for an AI algorithm to determine the common characteristics associated with a stock character for a literary work when it comes to the scènes a faire doctrine. Furthermore, for theatrical works, it may be easy for an AI algorithm to determine literal copying of words from a novel or film but difficult for an algorithm to determine copying elements from the plot, characters, or settings.

Finally, as with any novel application of a new technology, gamesmanship may be used to create confusion for the algorithm. Specifically, "bots" that run automated tasks over the Internet may work to confound the algorithm. In a fashion similar to Amazon's Mechanical Turk, bots can be used to generate random data that can act to jumble the results produced by an algorithm. ${ }^{192}$ Although at least one commentator did not find evidence of a "bot epidemic," he did find at least five to seven percent engaged in "trolling" or satisficing. ${ }^{193}$

\section{CONCLUSION}

It is clear that the substantial similarity test for copyright infringement, especially when applied to musical works, is inconsistent at best and notoriously confusing and unjust at worst. Judge Frank Easterbrook opined on the ordinary observer test stating, "[a]fter 200 years of wrestling with copyright questions, it is unlikely that courts will come up with the answer any time soon, if indeed

\footnotetext{
189 Fishman, supra note 12, at 1908. Note, however, that Fishman prefers the unidimensional melodic analysis over the multidimensional alternative of trying to "weigh the importance of multiple, interrelated dimensions simultaneously," which AI would be attempting to accomplish.

190 Id.; Nichols v. Universal Pictures Corp., 45 F.2d 119, 121 (2d Cir. 1930); see also Jeanne C. Fromer, Claiming Intellectual Property, 76 U. CHI. L. REV. 719, 782 (2009).

191 Fruehwald, supra note 26, at 35 ("The best available evidence on the issue of independent creation is undoubtedly testimony of experts in musical composition." (internal citation omitted)).

192 Douglas J. Ahler, Carolyn E. Roush \& Gaurav Sood, The Micro-Task Market for Lemons: Data Quality on Amazon's Mechanical Turk (July 29, 2020) (manuscript); see also Emily Dreyfuss, A Bot Panic Hits Amazon's Mechanical Turk, WIREd (Aug. 17, 2018, 11:38 AM), https://www.wired.com/story/amazon-mechanical-turk-bot-panic/.
}

193 Ahler et al., supra note 192. 
there is 'an' answer, which we doubt."194 Although the problem is currently confined to the courts, the solution may be revealed through the fields of computer engineering and artificial intelligence.

Artificial intelligence and machine learning tools offer two elegant solutions to the problems associated with copyright infringement of musical works. First, AI can be used as an expert to help determine which portions of the referenced song are protected and which portions are in the public domain. Second, AI can be trained to act as an "ordinary AI observer." This AI observer can then act as an arbiter for infringement by determining if "too much" copying occurred.

The benefits of using an AI system are that it can be regressive and can evolve over time based not only on the algorithm but also on the training it receives under a supervised learning model. Because the algorithm can be regressive, it can create output to quantify how much protected copying has occurred (e.g., the algorithm could tell if a song contained $10 \%$ copyrighted material versus $85 \%$ copyrighted material). This information would help courts and/or the trier of fact determine if "too much" copying has occurred.

If musicians, producers, musicologists, copyright experts, and AI engineers could convene and create a standard algorithm for musical works, then there would be many benefits based on economies of scale. Specifically, all musical works could be compared when assessing what is functional and what might comprise scènes à faire. Additionally, works across all genres could be compared using the same set of standards.

Once a standard algorithm is created, legislators could set a specific amount of copying that would impart liability. Musicians and producers could determine their risk of copyright infringement before going to market. This system would allow musicians to change their songs before investing the time and money to market and distribute their works. Furthermore, producers and distributors could then better evaluate their true risk of copyright infringement. Finally, a standardized algorithm could take power back from platforms such as YouTube and Facebook and place power back into the hands of all copyright stakeholders instead of only those who wish to monetize copyrighted works. ${ }^{195}$

The costs and limitations of the use of AI to help determine copyright infringement should not be understated. First, there is a bias issue prominent with all AI algorithms in that humans will necessarily incorporate their biases into the algorithm. This issue may be addressed by creating a standard algorithm with input from all stakeholders. Second, there is a real concern with the fair use doctrine as AI and other algorithms will necessarily have a difficult time accounting for this defense. Luckily, fair use has not played a prominent role when it comes to copyright in musical works. Third, there could be a concern with transparency. However, much of this concern can be alleviated through the

\footnotetext{
194 Nash v. CBS, Inc., 899 F.2d 1537, 1540 (7th Cir. 1990).

195 Ruse-Khan, supra note 16.
} 
use of technology that makes the AI decision-making process more understandable and visible. Finally, this Article suggests that AI be used in this manner only for musical works and should not be expanded to other copyrightable subject matter.

Courts and commentators have come to condemn the "substantial similarity" requirement. Its structure, scope, and purpose continue to confound courts and scholars. ${ }^{196}$ One possible solution comes not from the courts or Congress, ${ }^{197}$ but from computer science. Through the use of AI, courts, juries, musicians, producers, and distributors have a way to escape the gravity of the "virtual black hole in copyright jurisprudence."198 Musicians, producers, copyright experts, and courts should take advantage of this opportunity.

\footnotetext{
196 Shyamkrishna Balganesh, The Questionable Origins of the Copyright Infringement Analysis, 68 STAN. L. Rev. 791, 794 (2016).

197 Id. at 863 (stating that Congress played no role in the development of the infringement analysis).

198 Id. at 794.
} 